\title{
Symbolism of UMaT's Emblem, Flag and Ceremonial Mace - Conglomeration of the University's Essence and Aspirations*
}

\author{
M. F. Annku and D. Mireku-Gyimah
}

Annku, M. F. and Mireku-Gyimah, D., (2009), “Symbolism of UMaT’s Emblem, Flag and Ceremonial Mace Conglomeration of the University's Essence and Aspirations”, Ghana Mining Journal Vol. 11, pp. 69 - 74.

\begin{abstract}
The University of Mines and Technology (UMaT), Tarkwa was established in November 2004 by Act of Parliament (Act 677) after successfully passing through four exciting levels of erudition. It was concurrently identified by an emblem and a flag as a creditable sovereign institution. On 25th July, 2009 UMaT introduced its first ceremonial mace to be experienced at its first's congregation. This paper brings to the fore the concepts and philosophical dimensions of the emblem, flag and ceremonial mace as unique symbols of UMaT's erudition, integrity and authority.

Part of the concepts are based on studies from traditional and contemporary iconography including Adinkra and Agama traditional symbols for a gratifying symbolic and aesthetic blend. Apart from exploring the cultural background of UMaT, this material is intended to be used as a reference material for educators, historians, and other researchers in related fields and above all preserve UMaT's rich cultural dimensions.
\end{abstract}

\section{Origin and Concepts of Symbols of Power and Authority}

The use of symbols can be traced as far back as the Paleolithic Art (or cave art over 11000 years ago) through the Feng Shui Horse which is a symbol for authority, power, success and growth (Guru, 2007), to the Crucifix (Fig. 1) which symbolizes the death, faith and resurrection of Jesus Christ and considered the perfect symbol of Christ's crucifixion in the Christian religion. These symbols are essentially an object or iconography which may represent a person or an authority, and express an idea, value, or quality; animate or inanimate.

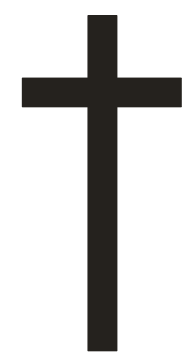

Fig. 1 The Crucifix

Among the Akans and Ewes in Ghana, such symbols represent the cultural heritage and natural treasures of the people in terms of attitudes, beliefs and values. These symbols that normally encode knowledge or wisdom, economic, agricultural or cosmic views are mainly associated with the regalia of Chiefs' palaces

\footnotetext{
* Manuscript received July 9, 2009

Revised version accepted November 5, 2009
}

and courts. As noted by Arthur and Rowe (2003), "the regalia of Ghanaian chiefs have been of special significance ... not merely symbols of the kingly office but have served as the chronicles of early history and the evidence of traditional religion, cosmology and social organisation ... and paraded whenever the chief appears in state at a festival or durbar". The simple graphic presentations of the Ghanaian indigenous symbols similar to the Crucifix come as emblems on palace walls and other substrates like fabrics (flags), wood or metals (linguist staffs). The reference to festivals and durbars suggests that people who may experience the symbols may read, mark and inwardly digest the deep and surface aesthetics of these symbols thereby promoting an important medium for cross-cultural understanding.

The use of ensigns (flags) is not limited to state coronations or chiefs' courts. The symbol of authority which John Cabot set up to claim Newfoundland territory in 1497, for Henry VII of England, was "the royal banner" (Croxton, 2009). And the Asafo Company (warrior group) of the Fantepeople from Ghana designed its own flag, to express its own power and might (Bakker, 1999). Studies of many Asafo ensigns for this article show elaborate pictograms carefully selected, as it were, to spell the inferiority of the adversary. Ghana, like other sovereign states, is identified by the National Flag (Fig. 2) made up of four significant colors: red, yellow, green and black (a star in the middle of the golden yellow). The red signifies patriots 
who fought and shed their blood to gain independence for Ghana; yellow represents the mineral wealth of Ghana and green the agricultural wealth of Ghana. The black star stands for the hope of Africa.

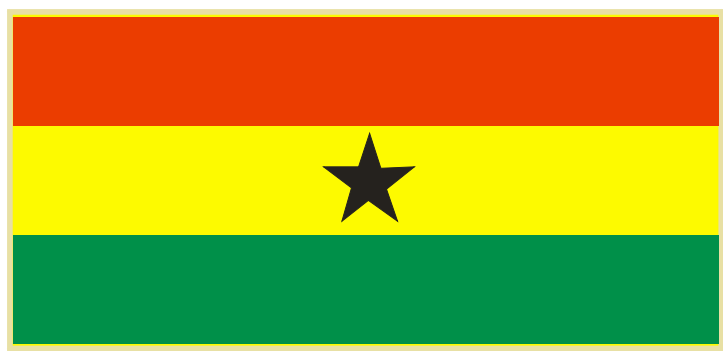

Fig. 2 The Ghana Flag

The mace derives from an ancient club-like weapon that was later adapted as a ceremonial symbol of authority by the Babylonians and Assyrians as early as $700 \mathrm{BC}$. This decorated version was also used to protect the king's person, borne by the Sergeants-at-Arms, a royal body guard established in France by Philip II (Anon, 2008). The significance of the mace has gone beyond its original use as a medieval weapon. Today, it has been transformed into a highly ornamented staff of metal and wood carried before a sovereign or high official as a symbol of authority in rituals and processions. Indeed, according to Galloway (2008), in Canada's Parliament, the legislators have no authority under which to make or repeal laws until the mace has been placed on the table before the Speaker's chair.

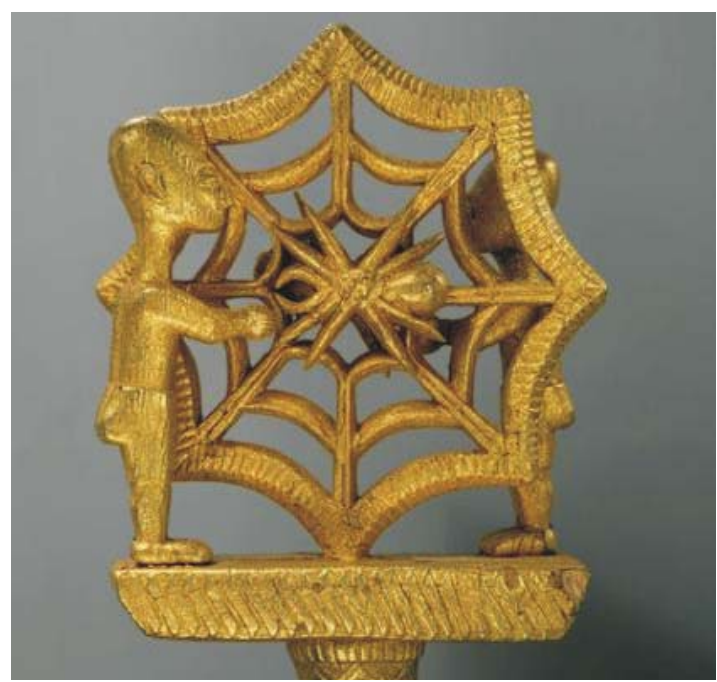

Fig. 3 The Finial of Traditional Linguist Staff

In Ghana, the traditional linguist staff is identical to the modern ceremonial mace. It derives from The European "messenger sticks" (Holcombe,
1984). The staffs are often carved out of wood and topped with sculptural artifacts that represent proverbial messages and carried by the linguist before the chief as a symbol of the chief's authority. The messages were intended to constantly remind the chief and his subjects of basic values and morals. Fig. 3, for example, shows a typical linguist staff from Ashanti. The finial illustrates two human figures flanking a large web with a spider at its centre and refers to the proverb "no one goes to the house of the spider to teach him wisdom". Here, the spider, personified Kweku Ananse, the originator of Akan folktales and proverbs is considered the ultimate repository of erudition similar to the linguist, neither of whom should be challenged in their respective domains of jurisdiction. In other words, the linguist staff has encoded power and authority identical to those vested in the uniform of any state policeman, to the extent that unannounced presence of the linguist staff at any time of the day in a citizen's house means he or she is being summoned to the Chief's palace without question or hesitation.

The birth of a sovereign state, formidable organization or a creditable institution is normally associated with a number of symbolic coronation paraphernalia. As noted above, and very often, they come in the form of a regal artifact (iconography) and a related hagiography (Tyler, 2008). However, for the purpose of this material, three main symbols of power and authority and the anthem (hagiography) are considered. The symbols are the emblem (crest or logogram), a flag, and the ceremonial mace. These symbols, often expressed in art forms and literature epitomize the philosophy, core values and, to a large extent, the corporate identity of the particular sovereign state, institution or system.

\section{Design and Concepts of UMaT Sym- bols of Authority}

When UMaT emerged as the sixth public university in Ghana, after successfully surviving four exciting levels of erudition: the Tarkwa Technical Institute, Tarkwa School of Mines, KNUST School of Mines and Western University College. It became necessary to evolve unique symbols that will perpetually exude the essence and aspirations of UMaT. The three main symbols that needed to be designed were the UMaT Emblem, UMaT Flag and the UMaT Ceremonial Mace.

\subsection{UMaT Emblem}

With the establishment of UMaT, like many 
other creditable institutions, there was immediate need for UMaT insignia. The Audio Visual Unit (AVU) of the University was taxed to design a unique insignia for the University. The AVU in collaboration with the Vice Chancellor (VC), Prof. Mireku-Gyimah and few others evolved the UMaT emblem and flag in November 2004, from the University's mission and vision statements. It is worth noting that as early as October 2004, the VC's hagiographic work on the anthem surpassed four other presentations and was consequently adopted for the University.

The University's emblem engraved on a classic shield (a protective device, meant to intercept attacks), epitomizes the need at all times, as it were, to protect the acquisition of knowledge, truth and excellence in the fields of mining, technology, engineering and other related disciplines based on sound theory (symbolized by the book) and good practice (symbolized by the geological hammer and the cog wheel). The result is a fulfilling wisdom that radiates (like the rising sun) in the lives of all and sundry who imbibe this wisdom from UMaT (Mireku-Gyimah and Annku, 2005). The black eruption from the base is also symbolic of mineral ores including petroleum from the bowls of the earth for scientific and technological analysis and processing through studies (again symbolized by the book). At the base of the shield is a golden ribbon in which the core values of UMaT knowledge, truth and excellence is inscribed.

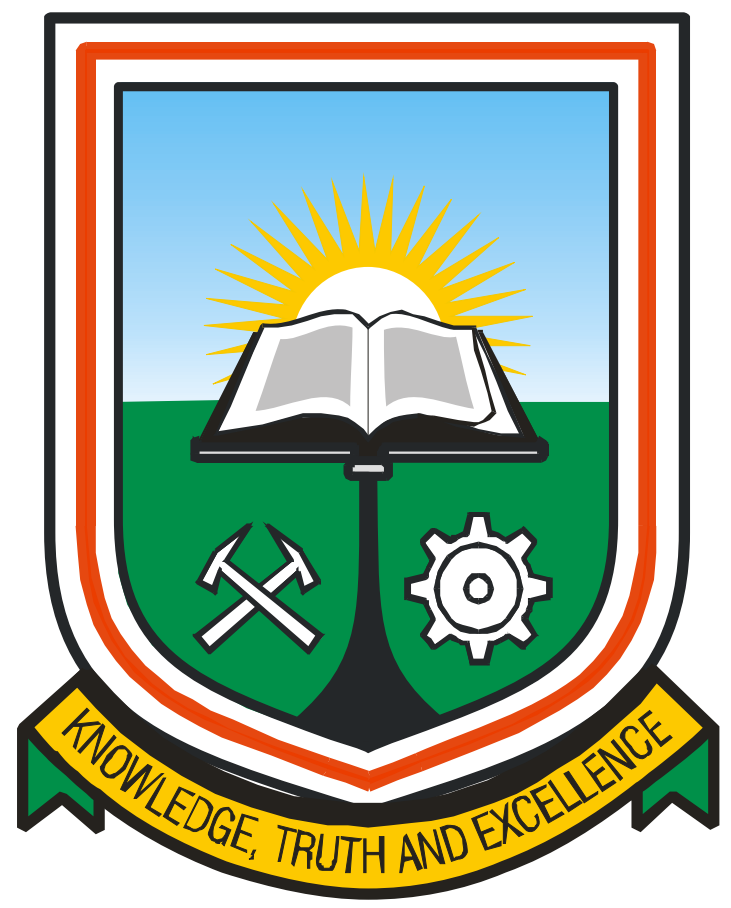

Fig. 4 UMaT Emblem
The chromatic data that tang and give fuller meaning to the emblem did not come from void. Fig. 4 shows UMaT emblem (having a standard width to height ratio of 1:1.26) in its standard flat colours: emerald green (growth), sky blue, modulated to single out UMaT's unique serenity (peace), scarlet red (bravery - UMaT's virtue galvanized by the blood and toil of the founders of UMaT), golden yellow (elevation of the mind), black (solidity) and white (purity) as background colour. The predominant colour, green, also doubles as the colour of the evergreen forest of the Western Region of Ghana where UMaT is located. The strict proportionality between the symbols and the strong intensity of the colours symbolize discipline and the admiration of the beauty of God's geometric creation of the universe.

The eventual crystallization and acceptance of the emblem by which the University would be identified, in terms of legal documentations (seal and certificates), sovereignty, power and authority also culminated into the University flag as the second symbol of authority.

\subsection{UMaT Flag}

UMaT flag as the second symbol of authority, is rectangular in layout, and reflects two prominent colours: the background colour, cream (3\% cyan, $11 \%$ magenta and 25\% yellow) symbolizing UMaT's uniqueness is her choice of colour for building structures, while the green belt $(7 \mathrm{~cm}$ wide) across the mid length of the cream background represents the vivid greenish landscape in which the structures are set (Fig. 5).

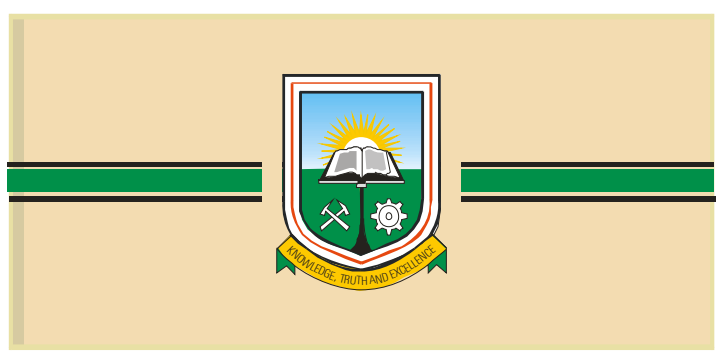

Fig. 5 UMaT Flag

Perhaps, the most suitable substrate, to carry the emblem, is fabric material. This is largely because of its flexibility, texture and ability to withstand vagaries of the weather over a long period. UMaT ensign or flag has a vibrant inscription of the University emblem, CAD printed and heat transferred, on each side of the fabric material. As a symbol of authority, it does not only symbolize and define UMaT's territory as a creditable institution but also serves as coronation paraphernalia. It was adopted and hoisted on the $7^{\text {th }}$ of November, 2004. 
Though flags have no universal standard size and come in a variety of sizes, a square or an oblong, UMaT has a unique standard size of $90 \mathrm{~cm}$ by 120 $\mathrm{cm}$ that translates in the ratio of $1: 1.3$. The height of the flagpole is, however, based on the international standard of three or four times the length of the flag (Anon, 2009).

\subsection{UMaT Ceremonial Mace}

The ceremonial mace, the third legal artifact or symbol of power and authority, is a necessary catalyst in academic ceremonies. Indeed, its use is not limited to the academia but nations, parliaments, religious communities, public and secret societies and countless other organizations around the world possess symbols of authority under which their citizens, adherents or members respond to the laws and regulations that govern and sustain them (Galloway, 2008). Symbols of authority come in many other forms like crowns, coats of arms, and seals.

Prof. Mireku-Gyimah conceived the idea for a unique UMaT ceremonial mace in January, 2007 and immediately taxed Dr. Annku to design a simple, unparalleled mace with an in-depth royal touch. Research results, on the history, form, artistry and symbolic significance of maces as far as UMaT's traditions, values and aspirations are concerned, were analyzed and synthesised into an acceptable visual presentation. It draws on the original simple but lethal weapon of a wooden or metal shaft with a heavy head made of granite, copper, bronze or iron to deliver powerful blows.

A blend of conceptual art and aesthetics, within the realms of traditional and contemporary presentations, has been the fulcrum for the studies in attempt to evolve UMaT's ceremonial mace. In this context, conceptual art is perceived as the "appreciation for a work of art because of its meaning while the aesthetic value is derived from the shape, color, and composition of the work (Christman, 2003).

The work is thus uniquely crafted from traditional linguist staffs and contemporary maces. The position of UMaT as a science-based institution with emphasis on mining and related engineering disciplines and having reputation for excellence in teaching and research, delivery of practical solutions that improve quality of life and the environment have been deeply symbolized in the areas of authority, integrity and the core values of the University. During the formative stages, shorter mace design was considered but set aside in favor of $150 \mathrm{~cm}$ in height (Fig. 6). This is preferred in order to provide more physical space to comfortably accommodate the green rope tassels and also march the average height of the bearer.

UMaT mace is divided into three main chromatic sections. The three (3) main chromatic sections

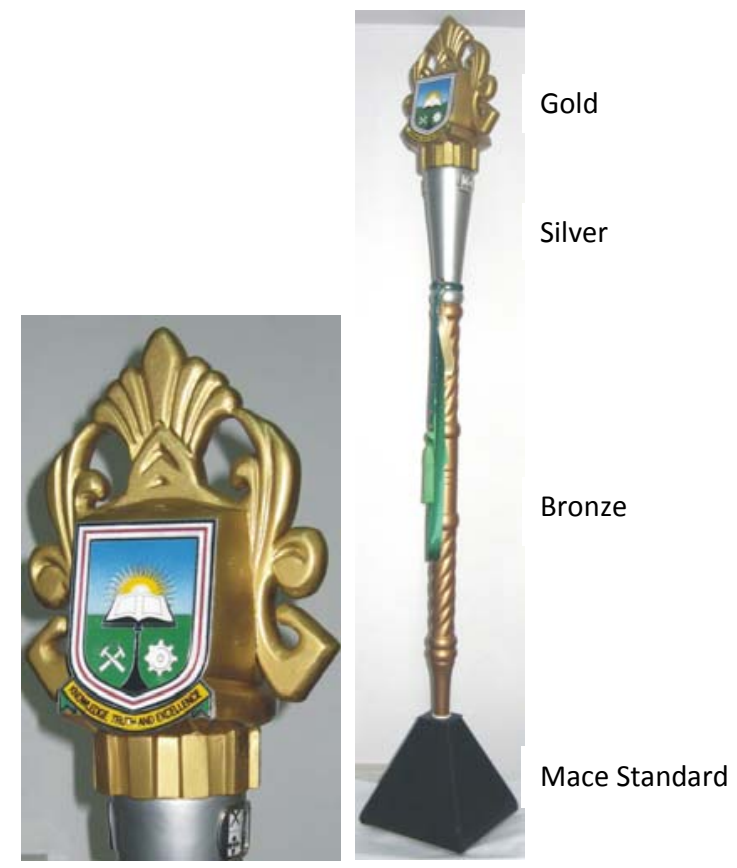

Fig. 6 UMaT Ceremonial Mace

are from the mace standard, bronze, silver and gold. The bronze represents undergraduate students who would obtain Bachelor degrees, silver represents all postgraduate students who would obtain Master degrees and gold represents doctoral students who would obtain Doctoral degrees. These colours also translate into the seals on their respective graduation certificates.

The finial measuring $30 \mathrm{~cm}$ x $15 \mathrm{~cm}$, for good visual impact bears the seat of authority. Firstly, the royal throne on which the emblem (Chancellor or the Vice Chancellor) sits relates the investiture and inauguration of the University as an autonomous institution in 2004 by parliamentary Act 677. The royal throne, Ohene Adwa or stool, encodes the traditional philosophical construct of state territoriality. As Preston (1973), points out, the ohene adwa exists in relation to specific laws of custody of the earth, asase, and this custody has its origins in prime occupancy of territory which is considered a de facto sacred act. In principle, we would say where there is no stool (mace) there is no state. This philosophical dimension makes the mace and other symbols a sine qua non.

Secondly, the base of the stool is shaped from the cog wheel that depicts engineering. The series of projections (lecturers) on its edge, transfers motion (wisdom) by engaging with projections (students) on another wheel (the two other spiral cog wheels shaped in the main staff.

Thirdly, to underscore that UMaT is a coeducational institution, the mace caries a male and 
female student as a floral design emanating from two opposite sides of the symmetrical finial while the two emblems are fixed in the other two sides to give the entire finial a royal touch.

The mace has also been given a strong traditional touch by incorporating Adinkra Symbols to buttress authority and core values (Agbo, 2006). These are found in the Akofena symbol of Authority, advising people to honour and show loyalty to their elders and encouraging statesmanship and gallantry; Dame-Dame symbol of Intelligence, encourages brain exercise and stresses the need to take sound and reasonable decisions (synonymous to the book used in the University's emblem for knowledge); Akoma Ntoaso, the symbol of Understanding, encourages people (UMaT and the society) to seek the truth (synonymous to truth in UMaT's core Values) and Nsaa the symbol of Quality advises us to eschew mediocrity and always aspire for excellence. Fig. 7 shows the four symbols.

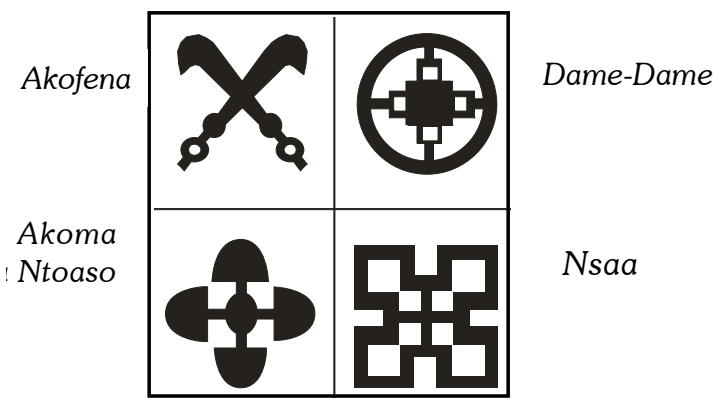

Fig. 7 Adinkra Symbols

\section{Significance of UMaT Symbols of Authority}

Perhaps the need to be easily and uniquely identified among equals in a highly protected and conducive environment is a fundamental rationale for evolving symbols that point to deeper truths usually experienced by individuals or as members of a particular culture. The UMaT emblem and ensign are a sine qua non as far as UMaT documentations and property ownerships are concerned. The wearing of lapel pins with UMaT insignia also spells out ones relationship with the University.

UMaT ceremonial mace comes as a metaphor for authority: learning and scholarship as well as eternal values apparent in UMaT history. It is also symbolic of that intrinsic power and authority vested in the VC which by tradition is handed over by an outgoing VC to an incoming VC. This ritual is analogous to the transfer of democratic powers from an incumbent president to a newly elected president of a sovereign state.
Again, it "guards" the Chancellor or the Vice Chancellor in the tradition in which the medieval sergeant-at-arms marched as bodyguards of kings and princesses (Anon, 2008). The final placement of the mace will signify the official beginning of all major University ceremonies like matriculation of fresh students, congregation ceremonies for the conferment of degrees and awards or the presentation of inaugural lectures.

Finally, it also serves as a unifying force that connects current matriculation and congregation proceedings with the past, a repository of UMaT's roots and reputation for knowledge truth and excellence. It will be useful in understanding the relationship between authority and imagery.

\section{Conclusion and Recommendation}

It is hoped, as UMaT positions itself as a unique institution for excellence in mining and related disciplines in sub-Sahara Africa, it will equally continue to aspire to excel in everything that it does or represents. UMaT's authority over knowledge, truth and excellence vividly summarised in the emblem, flag and mace will reign supreme and radiate in the positive development of the nation. Indeed, below the surface meanings of the emblem, ensign and the mace can be found UMaT's guiding philosophy to develop student's intellectual capabilities and appreciate good social and moral values so as to produce world-class graduates capable of providing useful professional services.

Nevertheless, in as much as these symbols of authority nurture UMaT's rich cultural heritage, it is imperative to patent them. Formal registration of these symbols and regalia accords exclusive rights, prerogatives and privileges as far as their use and authenticity of University documents are concerned. The unauthorised use of any of these symbols of authority either for advertisement (commercial use) or any attempt to deface them can then be comfortably and legally challenged in the courts. Ideally, it is imperative to capture these conditions in the Statutes of the University of Mines and Technology, Tarkwa.

\section{References}

Agbo, A. H., (2006), Values of Adinkra Symbols, Bigshy Design and Publications, KNUST, Kumasi, pp. 28-46.

Anon,, (2008), "Ceremonial mace", http://en. wikipedia.org / wiki, assessed on 10.10.09, p. 1

Arthur, G. F. K. and Rowe R., (2003), “Akan Cultural SYME Project Online” http:// www.marshall.edu/akanart, assessed on 10.10.09, p. 1. 
Bakker, J. (1999), “About Asafo company flags (Fante people, Ghana)”, http://flagspot.net/ flags/gh_asafo.html, assessed on 10.10.09, p. 2.

Christman, T., (2003), "Concept or Aesthetics: Why do we Buy Art?”, http://www.wvu.edu, assessed on 11.10.09, p. 1.

Croxton, D., (2009), “The Cabot Dilemma: John Cabot's 1497 Voyage \& the Limits of Historiography”, http://etext.lib.virginia.edu/journals, assessed on 11.10.09, p. 1.

Galloway, S., (2008), "Symbols of Authority”, http://www.thecanadianencyclopedia .com, assessed on 11.10.09, p. 1.

Guru, I. (2007). "Your expert on Indian Sciences" http://www.indusguru.com/feng-shui-curehorses-for-success-power-and-authority, assessed on 11.10.09, p. 1.

Holcombe, B., (1984), "Metropolitan Museum of Art”, http://www.metmuseum.org., assessed on 12.10.09, p. 1.

Mireku-Gyimah, D. and Annku, M. F., (2005), "UMaT Emblem, Flag and Anthem", unpublished report. University of Mines and Technology (UMaT), Tarkwa, 4 pp.

Preston, (1973), “Ohene Adwa-King's Stool”, Akan Political Beliefs Symbols, http:// www.marshall.edu/akanart., assessed on 12.10.09, 6 pp.

Tyler, M., (2008), "Symbols of Power and Authority: The Iconography of Late ThirteenthCentury Chapter Houses." http:// www.york.ac.uk/teaching/history/pjpg/ Chapterhouse.pdf., assessed on 12.10.09, 1 pp.

\section{Authors}

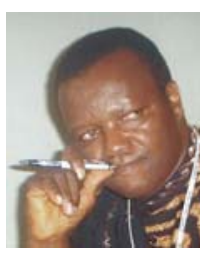

McBoafo Annku is a Research Fellow at the University of Mines and Technology, Tarkwa. He obtained his Bachelor of Arts Degree in Graphic Design, Postgraduate Diploma, Masters and Doctor of Philosophy Degrees in Art Education from the Kwame Nkrumah University of Science and Technology (KNUST), Kumasi, Ghana. Dr. Annku is currently the head of the Audio Visual Unit at the University of Mines and Technology. His areas of specialisation are in Educational Technology, Conceptual Presentations on environmental issues and Aesthetics. Some of his works include conceptual 3-D drawings of re-vegetated lands for Abosso Goldfields Limited and Sankofa Gold Mine in 1998 and 2000 respectively. He is a member of the Ghana Society of Education through Art (GhaSEA)

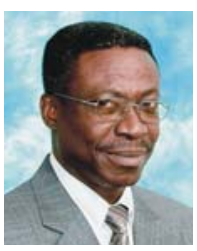

Prof. D. Mireku-Gyimah holds the degrees of MSc from the Moscow Mining Institute, Moscow, Russia, $\mathrm{PhD}$ and DIC from the Imperial College of Science, Technology and Medicine, London, UK. He worked at Prestea Goldfields, as a Technical Mining Assistant. In 1981, he joined the University of Mines and Technology, Tarkwa, Ghana, where he is now the Vice Chancellor and lectures in Mine Design and Planning, Mine Economic and Financial Evaluation, Operations Research and Computer Applications. He is a Full Professor of Mining Engineering and a Chartered Engineer. He is a member of Institute of Mining and Metallurgy (IMM) of UK, Society of Mining Engineers (SME) of USA, and the New York Academy of Sciences (NYAS). He is also a fellow of Ghana Institution of Engineers and the Ghana Academy of Arts and Science. 